\title{
Neuroprotection effects of ethyl acetate and n-butanol fractions of the hydroalcoholic extract of Tanacetum bodjnordens on sciatic nerve compression in male rats
}

\author{
Mehri Ghahri ${ }^{1}$, Maryam Tehranipour $^{\left({ }^{2}\right.}$, Jina Khayatzadeh ${ }^{\left(D^{2}\right.}$
}

\begin{abstract}
Background and Aims: When a neuronal axon is damaged, it returns to the neuron cell body and destroys it. Tanacetum bodjnordens as antioxidant and anti-apoptotic effects. This study aimed to determine the neuroprotective effects of ethyl acetate and n-butanol and hydroalcoholic extracts of Tanacetum bodjnordens on sciatic nerve compression in male rats.
\end{abstract}

Materials and Methods: In this experimental study, 36 male Wistar rats weighing 200-250 g were randomly divided into 6 groups $(n=6)$. In the control group, the right thigh muscle of the rats was split after the anesthetization of the rats, while in the compression and treatment groups, the sciatic nerve was compressed for 60 seconds. The plant extract was injected intraperitoneally on the day of compression and seven days later. After 28 days, samples were taken from the lumbar spinal cord subsequent to performing the perfusion method. Afterward, 7- $\mu \mathrm{m}$ serial sections were prepared and stained using toluidine blue stain after tissue passage. Eventually, the neuronal density of rats in the six groups was compared.

Results: Based on the results, the neuronal density in the compression group decreased significantly compared to controls and showed a significant increase in the hydroalcoholic, n-butanol, and aqueous phase treatment groups compared to that in the compression group $(\mathrm{P}<0.001)$.

Conclusion: According to the results, it seems that Tanacetum bodjnordens leaf extract has neuroprotective effects that promote the regeneration process in damaged neurons and these effects are higher in the aqueous phase fraction.

Keywords: Degeneration, Neuronal density, Neuroprotective, Tanacetum bodjnordens

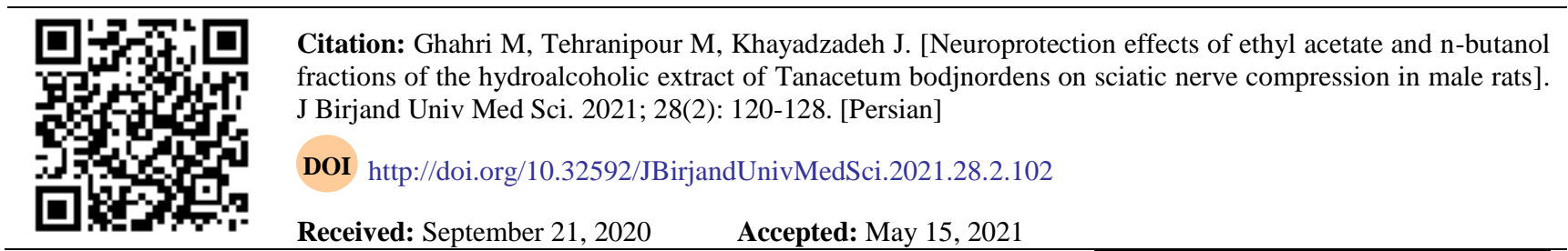

\footnotetext{
${ }^{1}$ Student Research Committee, Department of Biology, Faculty of Science, Mashhad Branch, Islamic Azad University, Iran

2 Department of Biology, Faculty of Science, Mashhad Branch, Islamic Azad University, Iran
}

Corresponding author: Department of Biology, Faculty of Science, Mashhad Branch, Islamic Azad University, Iran Tel: $+985138435050 \quad$ Fax: +985138435050

E-mail: maryam_tehranipour@mshdiau.ac.ir 


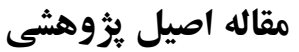

\title{
اثرات محافظت نورونى فراكسيونهاى اتيل استات و ان بوتانول عصاره هيدروالكلى برتى تياه مينا بجنوردى (Tanacetum bodjnordens) بر كمير سيون عصب سياتيك در رتهاى نر
}

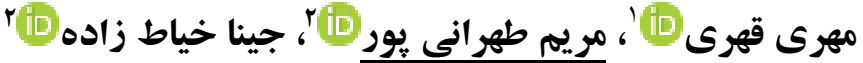

\section{جكيله}

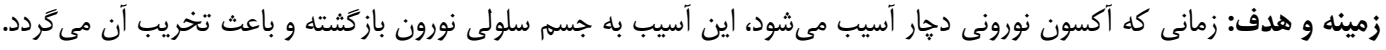

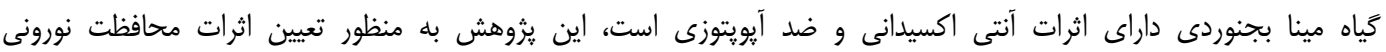

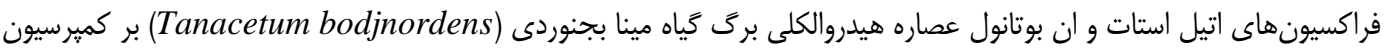
عصب سياتيك در رتهاى نر انجام شد.

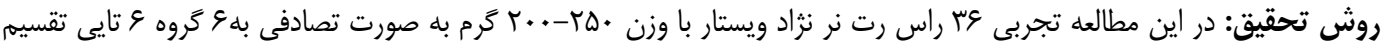

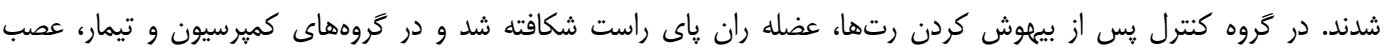

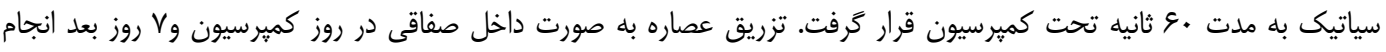

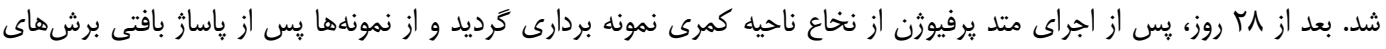

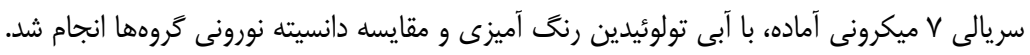

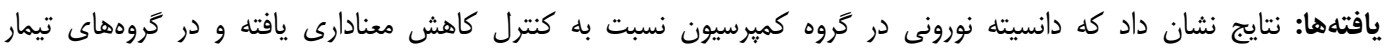

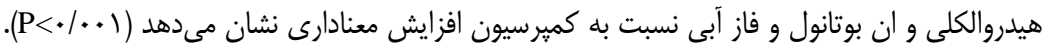

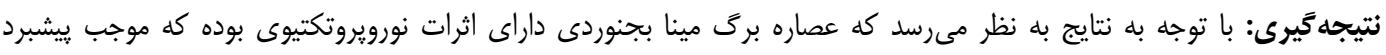

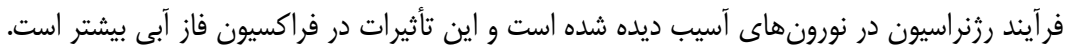
وازمهاى كليدى: دزنراسيون، دانسيته نورونى، محافظت نورونى، كياه مينا بجنوردى

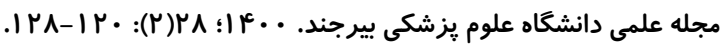

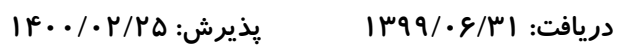

' كميته تحقيقات دانشجويى، كروه زيست شناسى، دانشكده علوم، دانشكاه آزاد اسلامى، واحد مشهل، مشهل، ايران

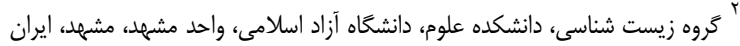
نويسنده مسئول: گَروه زيست شناسى، دانشكده علوم، دانشخاه آزاد اسلامى، واحد مشهد، مشهد، ايران

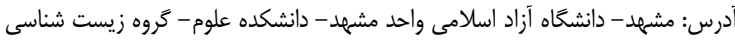

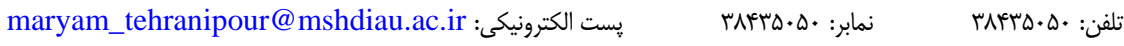


بلن بتواند شرايط را به سمت ترميم تغيير دهد دزنراسيون تبديل به

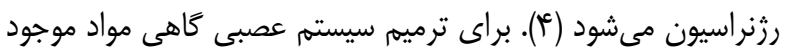

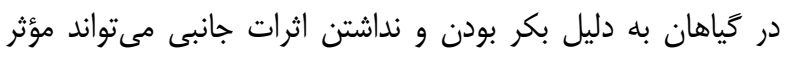

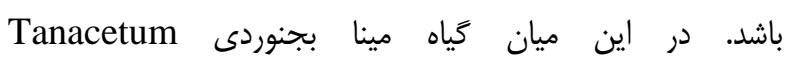
bodjnordens

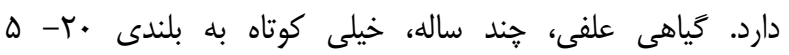

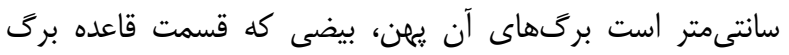

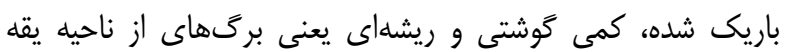

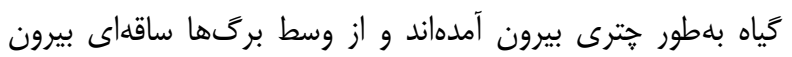

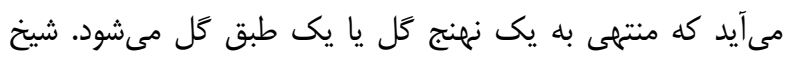

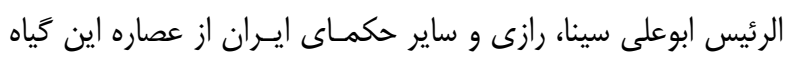

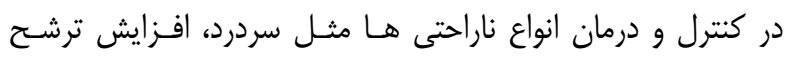

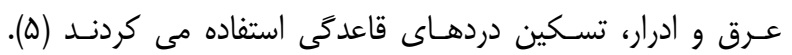

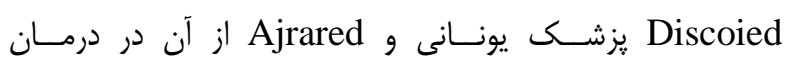

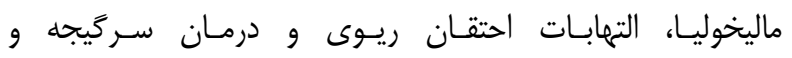

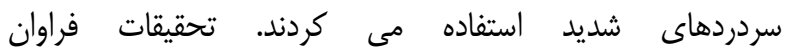

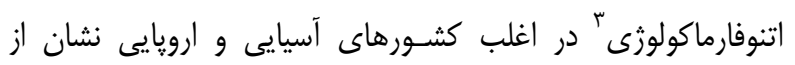

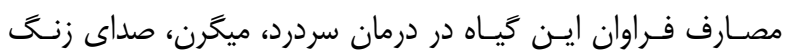

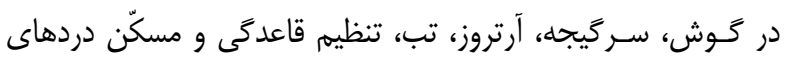

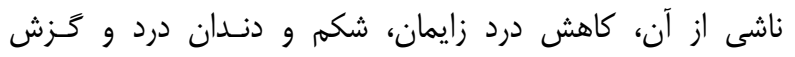

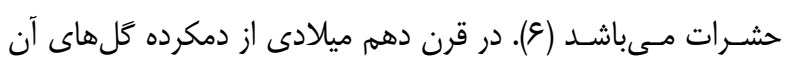

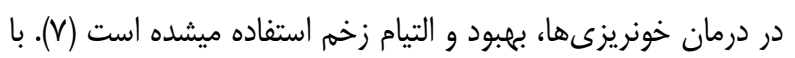

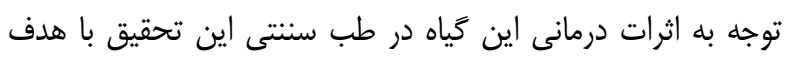

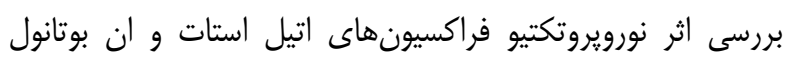

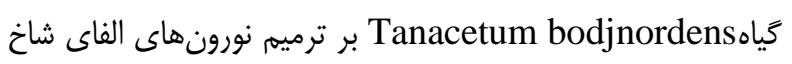
قدامى نخاع پِ از كمبرسيون عصب سياتيك در رتهاى نر انجام

\section{روش تحقيق}

در اين مطالعه تجربى برك گياه مينا بجنوردى از اطراف مشهد تهييه شده و توسط مركز هرباريوم دانشكده علوم پايه دانشكاه

\footnotetext{
${ }^{3}$ Etnopharmacology
}

مقلهم

جسم سلولى يك نورون محل سنتر اجزاى سيتويلاسمى و

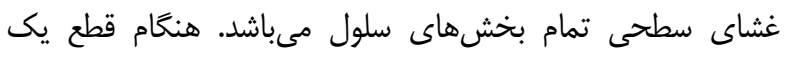

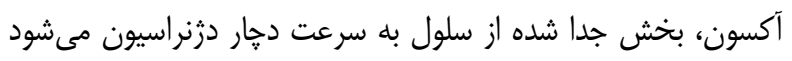
(1). غلاف ميلين نيز با وجود آن كه به وسيله نورون توليد نمى سلهود،

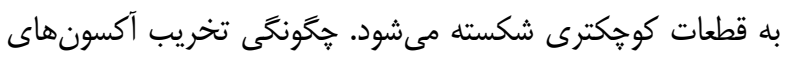

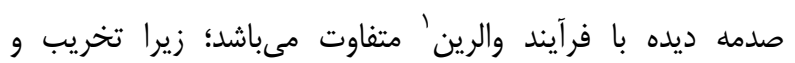
فاكوسيته كردن قطعات در سيستم عصبى مركزى با سرعت بسيار كمترى انجام مىشود. قطعات تخريب شده آكسونهاى ميلينه بعد از كاز

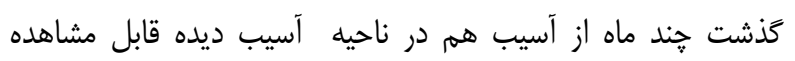

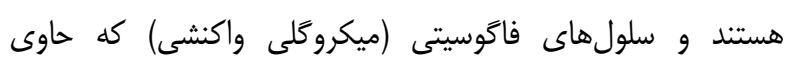
قطعات متلاشى شده مىباشد، بعد از جند سال در ناحيه آسيب ديده

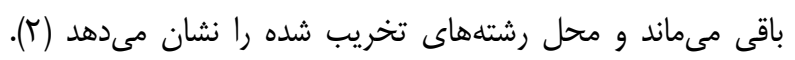

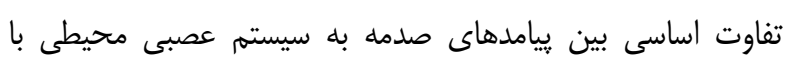

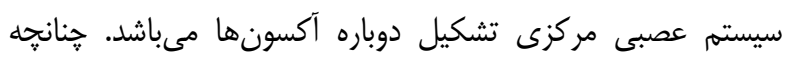

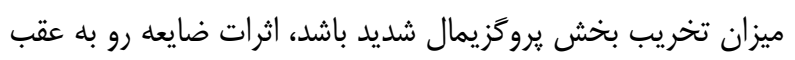

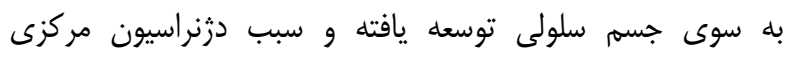

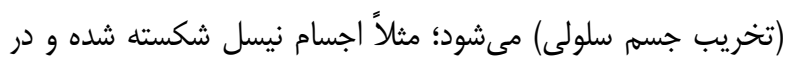

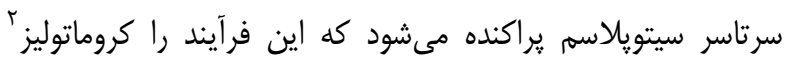

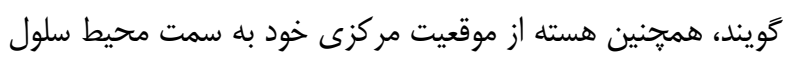
تغيير مكان مىدهد و جسم سلولى به دليل تغييرات اسمزى متورم

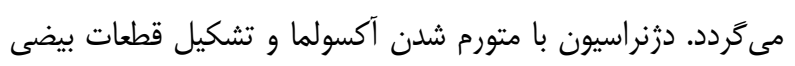

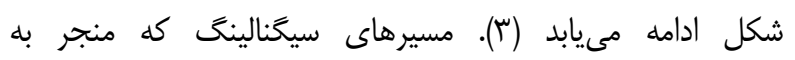
دزنراسيون آكسولما مىشود، ناشناختهاند و نشان داده شده كه آسيب آنابي

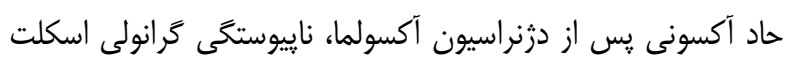

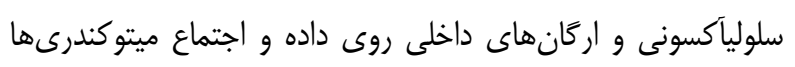

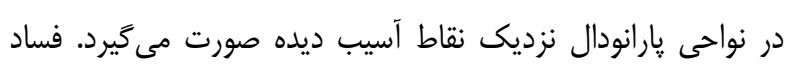

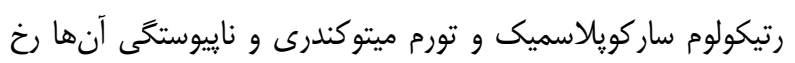

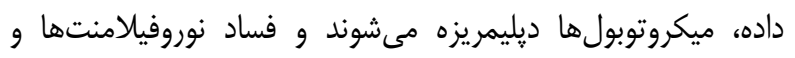

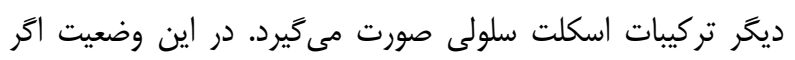

\footnotetext{
${ }^{2}$ Chromatolysis

${ }^{1}$ Valerain
} 
(قفل دوم) به مدت •ع ثانيه صورت كرفت. يس از كميرسيون عصب، محل ضايعه ضد عفونى و توسط گيره فلزى بخيه زده شد. در

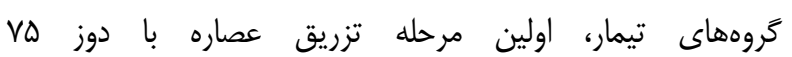

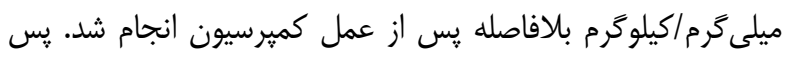

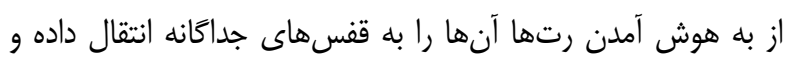

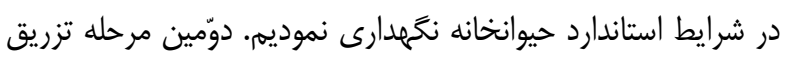

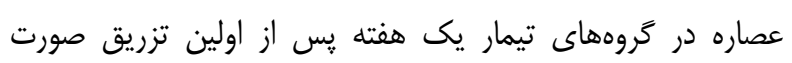

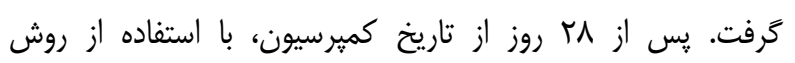

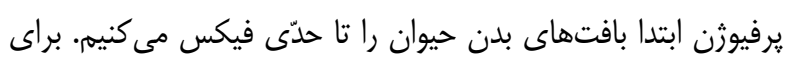

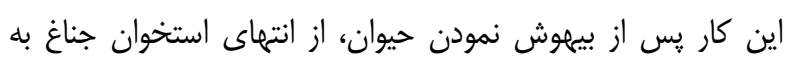

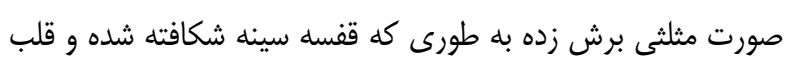

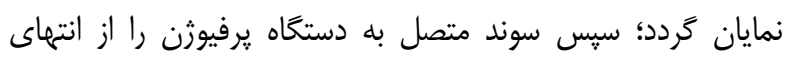

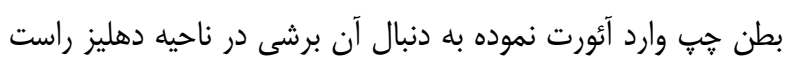

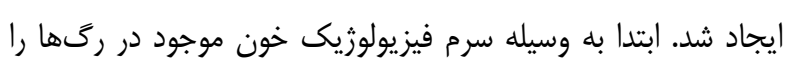

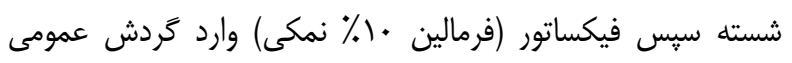

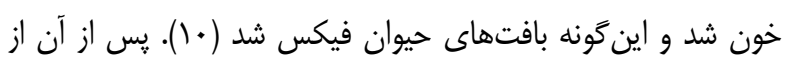

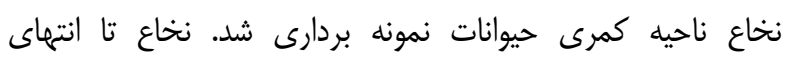

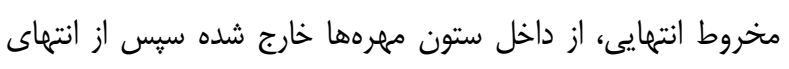

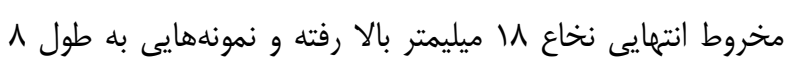

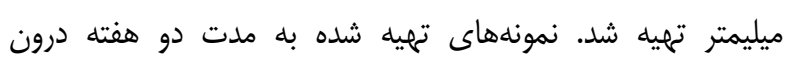

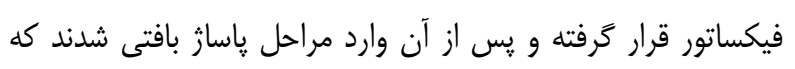

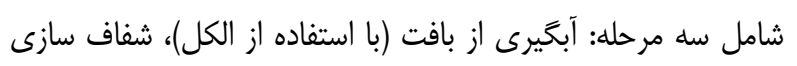

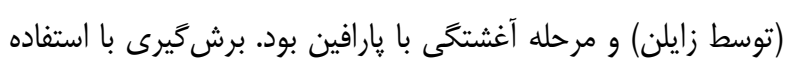

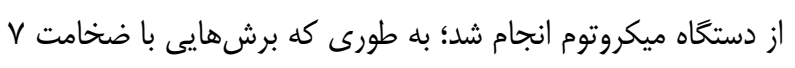

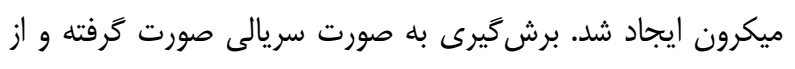

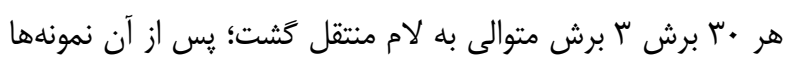

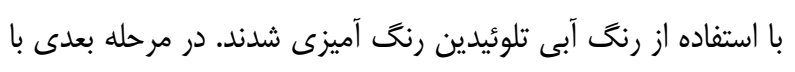

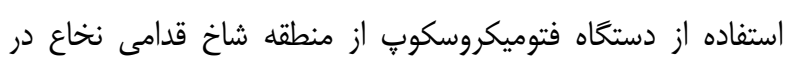

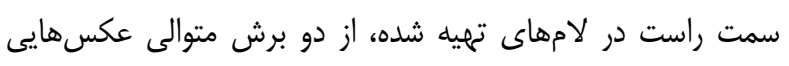

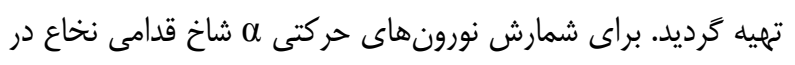

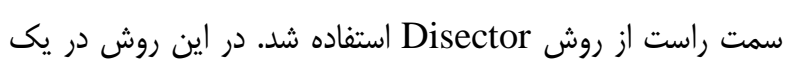

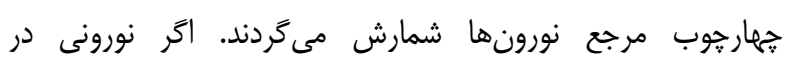

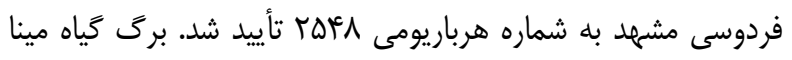
بجنوردى توسط دستكاه خرد كننده (آسياب) كاملاً آسياب كرديد.

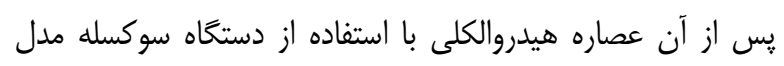

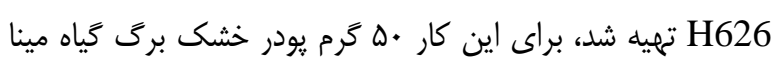
بجنوردى را داخل كاغذ مخصوص كارتوش ريخته در دستخاه قرار

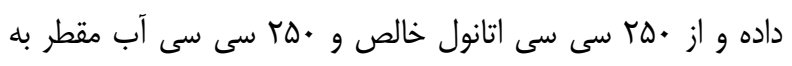

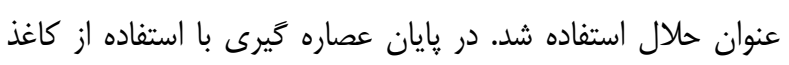
صافى عصاره فيلتر شده و سبس از عصاره هيدروالكلى حذف حلّال

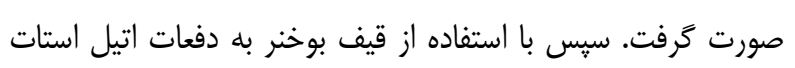

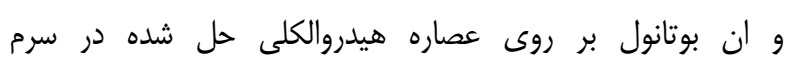

فيزيولوزى ريخته شد تا فراكسيونهاى مختلف جداسازى شد (^).

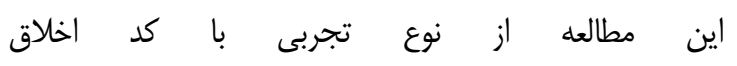
IR.IAU.MSHD.REC.1399.022 بوده است كه براى انجام

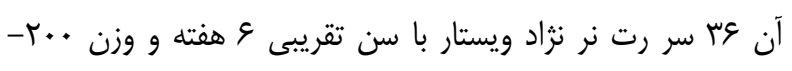

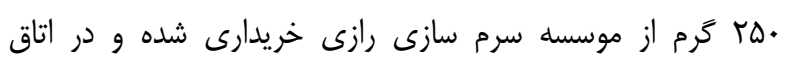

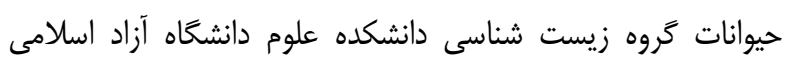

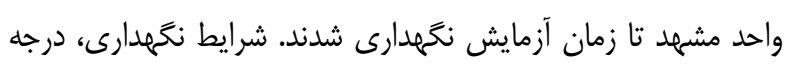

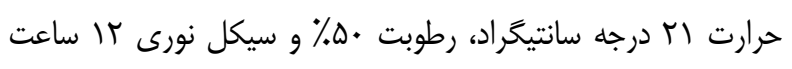

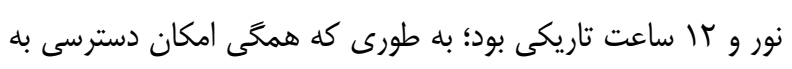

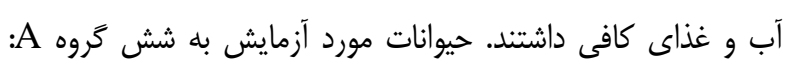

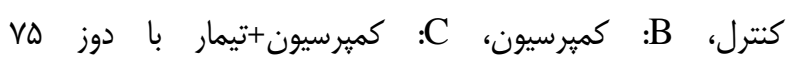

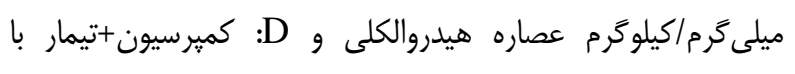

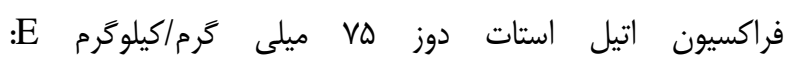
كمبر سيون+تيمار با فراكسيون ان بوتانول دوز VD ميلى گَرم اكيلوَّرم

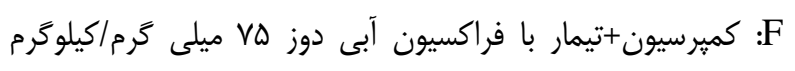

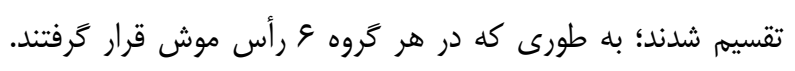

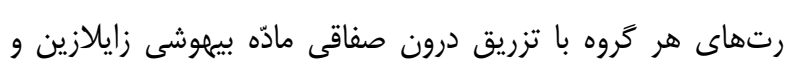

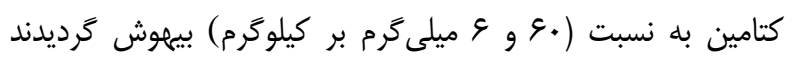

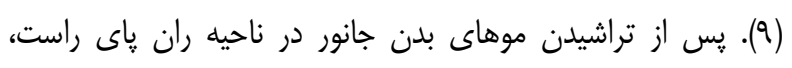

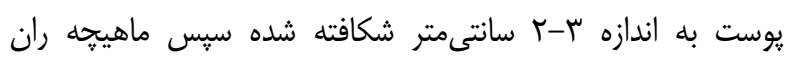
جهت مشخص شدن عصب سياتيك تحت جراحى قرار ترفت. عمل

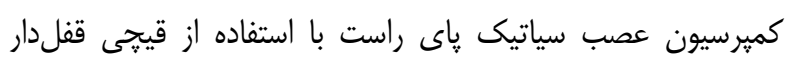




\section{يافته ها}

نتايج حاصل از بررسى ثديده دزنراسيون مركزى در طول ^ץ روز پِ از كميرسيون و همجِنين بررسى اثر محافظت نورونى كروههاى تيمار شده با عصارههاى هيدروالكلى و فراكسيونهاى اتيل

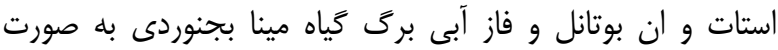
شمارش نورون هاى حركتى آلفا در شاخ قدامى نخاع در جدول ارائه كرديده است. در اين شمارشها براى يكسان شدن مقايسهها در

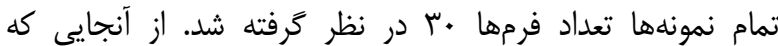

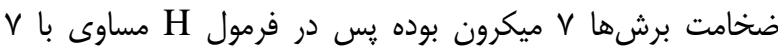

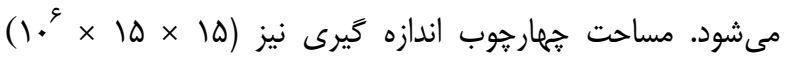

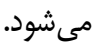

جهارجوب مرجع باشد؛ ولى در جهار خوب بعدى (در برش متوالى

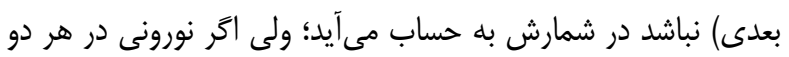
جهارجوب باشد در شمارش محسوب نمىشود (1). پِ از شمارش

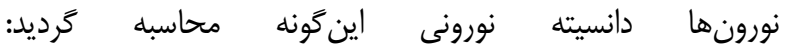
ND= $\mathrm{NQ} / \Sigma$ frame $\times \mathrm{V}$ dissector نورونهاى شمارش شده در يك نمونه است. Eframe: مجموع دفعات نمونه بردارى شده در يك نمونه است. disecector V: حجم هجهارجوب نمونه بردارى است كه برابر است با: dissector= A frame $\times H$ frame A نمونه بردارى است. H: فاصله بين دو برش متوالى يا ضخامت هر برش مىباشد. يس از به دست آوردن ND با استفاده از نرم افزار Minitab 13

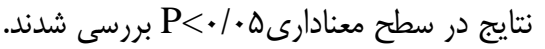

\begin{tabular}{|c|c|c|c|c|c|c|}
\hline فاز آبى & ان بوتانول & اتيل استات & هيدروالكلى & كميرسيون & كنترل & تروهها \\
\hline VETEIS & gIr土Tr & $r \Phi \Delta \pm r r$ & $\Delta \wedge \Delta \pm r V$ & $0 \cdots \pm 11$ & AFTETV & دانسي \\
\hline
\end{tabular}

جدول ا - تعداد نورونهاى شمارش شده در تروههاى مختلف

و كميرسيون تفاوت معنى دارى در دانسيته تعداد نورونها وجود دارد

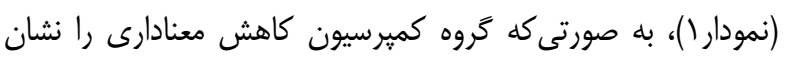

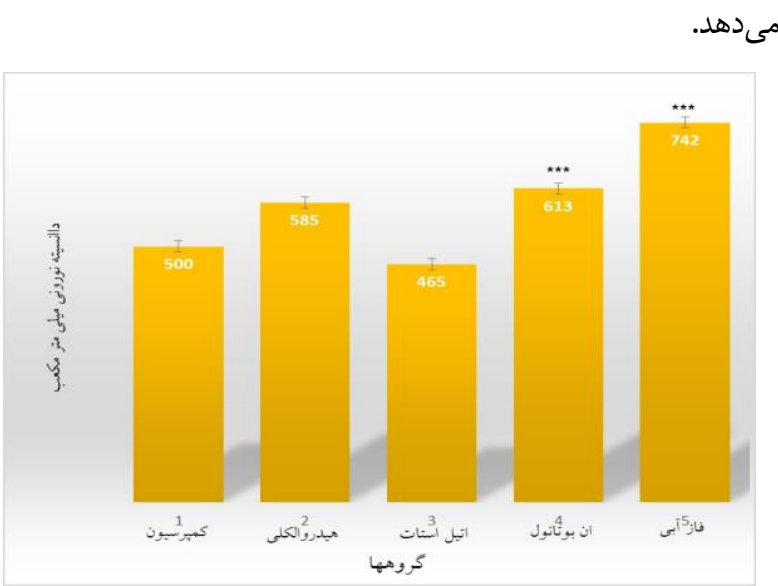

نمودار ץ- مقايسه دانسيته تعداد نورونهاى حركتى آلفا شاخ قدامى نخاع در كروه كميرسيون وكَوههاى تيمار (تعداد=ع). در هر كَروه اعداد نشان دهنده ميانگ̌ن ثلانحر اف معيار مىباشد.

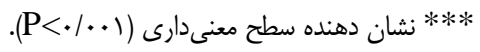

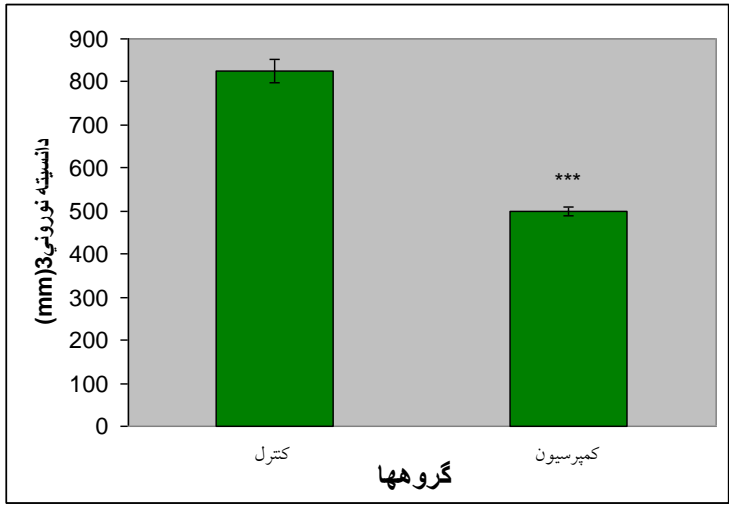

نمودار ا - مقايسه دانسيته تعداد نورونهاى حركتى آلفا شاخ قدامى نخاع در كَروه كنترل و كميرسيون (تعداد=ع) . در هر گروه اعداد نشان دهنده ميانگين ثانحراف معيار مىباشد.

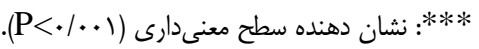
با توجه به | +.| Pشخص مىشود كه بين دو گروه كنترل 


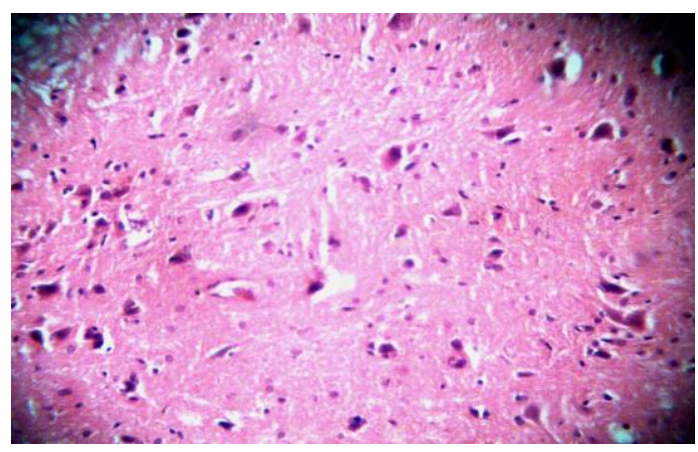

شكل س- برش عرض نخاع در تروه (كمير سيون+ تيمار با دوز

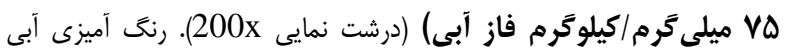
توليدين

جهت بررسى نتايج حاصل از تحقيق انجام شده تصاوير تهيه

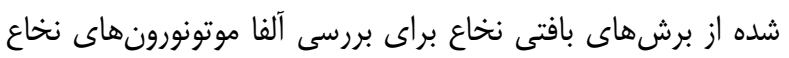

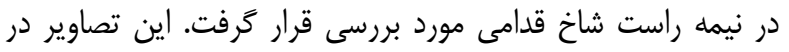

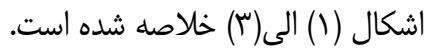

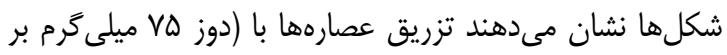

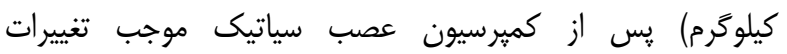
رزنراسيون در آكسون مىشود. به دنبال تغييرات رزنراسيون در آكسون، در بعضى گروهها جسم سلولى به حالت طبيعى در آمده و تورم سلولى كم مىشود. اين تغييرات در فاز آبى مشهودتر است.

\section{تحث}

همانطور كه در قسمت نتايج مشاهده مىشود، دانسيته تعداد

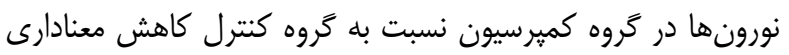

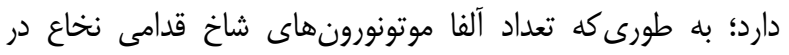
كروه كمبرسيون كاهش قابل توجهى داشته است و اين بدان

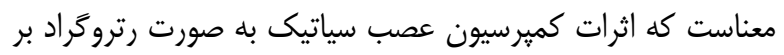
جسم سلولى نورونهاى حركتى در شاخ قدامى نخاع تأثير كذار بوده و سبب يديد آمدن دزنراسيون مركزى شده است. در ارتباط با مكانيزم احتمالى دزنراسيون مركزى نورونهاى آلفا

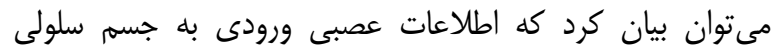
نورونهاى آلفا كه به طور طبيعى از طريق فيبرهاى حسى درياف الفت

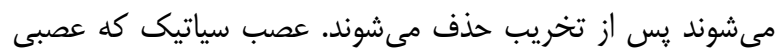

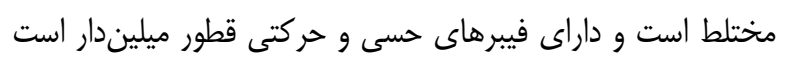

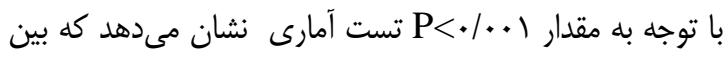

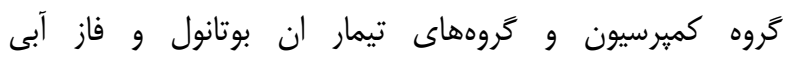

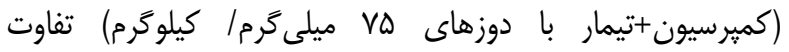
معنىدارى در دانسيته تعداد نورونها وجود دارد (نمودار r) و اين

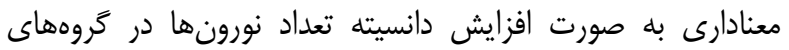

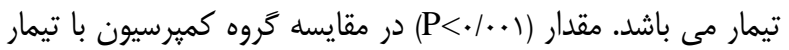
هيدروالكلى نيز افزايش دانسيته نورونى مشاهده مىشودد؛ ولى مئى معنى دار نيست. مقايسه كَروه كميرسيون با اتيل استات نشان داد كه

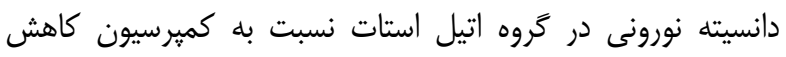
داشته است؛ ولى اين كاهش معنى دار نيست (P= (P= (P).

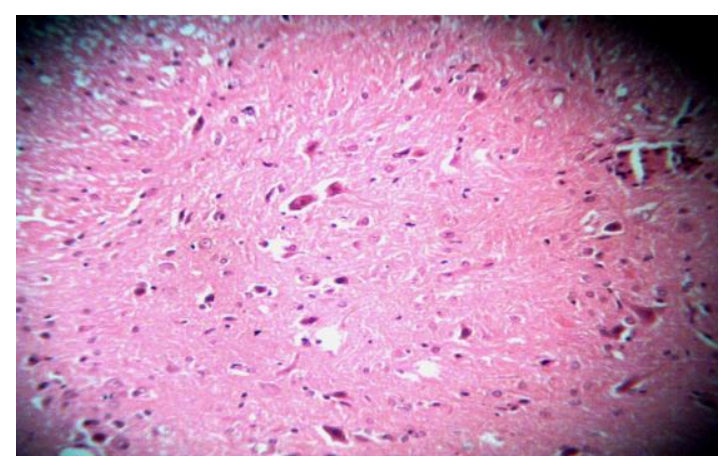

شكل ا- برش عرض نخاع در تروههاى كنترل (درشت نمايى 200x

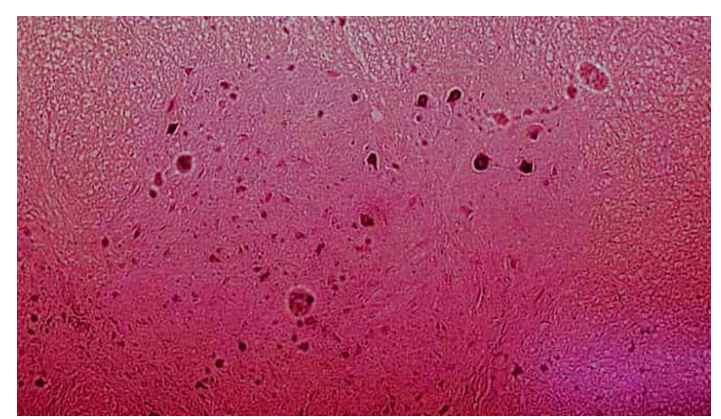
شكل r- برش عرض نخاع در تروه كمبرسيون (درشت نمايى

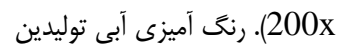


كزارش شده است. فلاونوئيدهاى مهم موجود در مينا بجنوردى

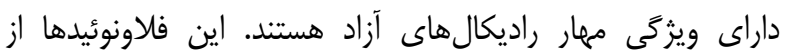

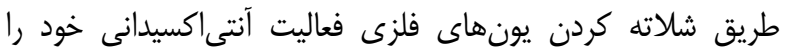

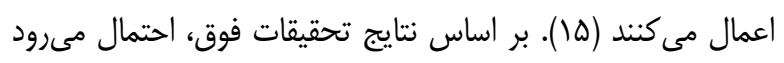

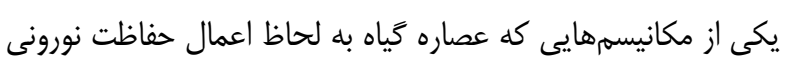
از آن بهره مىبرد، ويزخى آنتى اكسيدانى اين كَياه باشد.

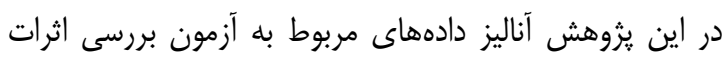

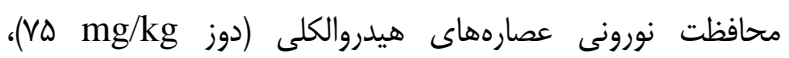
فراكسيون ان بوتانول (دوز VD mg/kg) و فراكسيون آبى (دوز از گ (Vهmg/kg كميرسيون عصب سياتيك در رت نشان داد كه دانسيته نورونى نانى كروههاى تيمار شده با عصارههاى فوق افزايش خشمخيرى نسبت

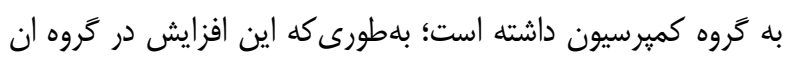
بوتانول و فاز آبى معنادار است.

مشاهدات فوق بيانكر آن است كه احتمالاً اين عصارهها حاوى

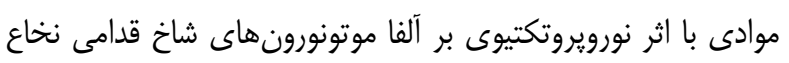

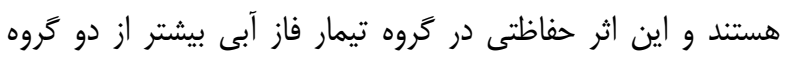
ديخر مىباشد. لذا مىتوان اين كونه توجيه نمود كه اجزاى مؤثر كياه

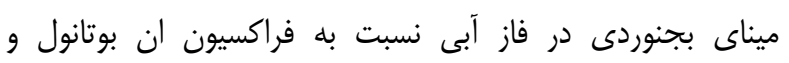
فراكسيون هيدروالكلى، به ميزان بيشترى وجود دارد. در كل مينا تركيبات سايونين، تانن، ماليك اسيد، وينيك اسيد، استيك اسيد،

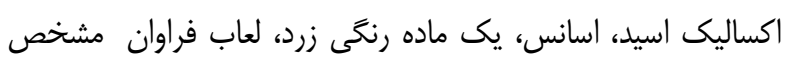
شده است (عا). يكى از تركيبات فلاونوئيدى مرهم موجود در اين زئن

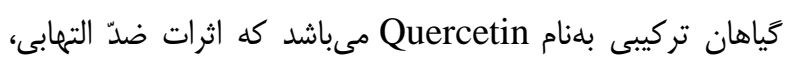

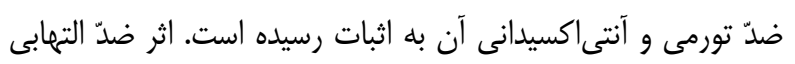

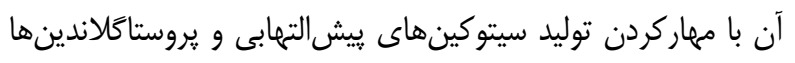

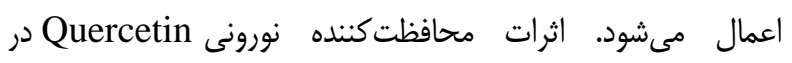
مطالعات حيوانى داراى ضايعات مغزى و نخاعى به اثبات رسيدات است. اين تركيب باعث كاهش ماكروفازها در محل آسيب مى خرد دد و

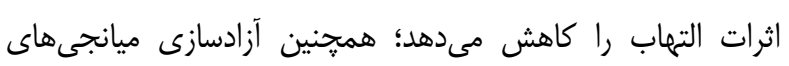

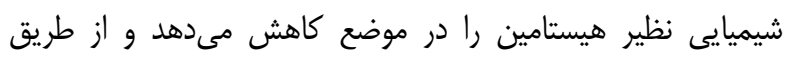

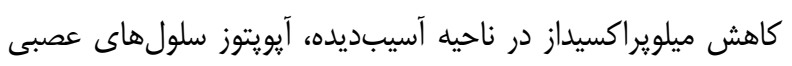

تحت كميرسيون كه قرار مى گيرد، فيبر حسى Ad نيز آسيب مىبيند

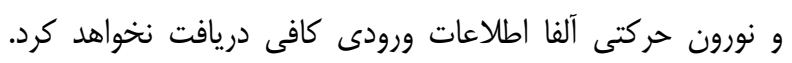
دوم اينكه قطع فيزيولوزيك آكسون نورونهاى حركتى آلفا موجب آنوات

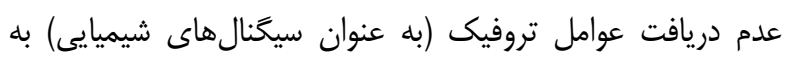

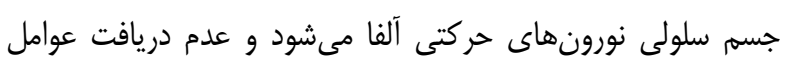

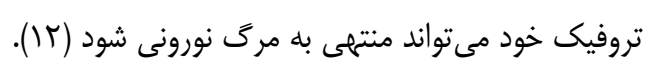

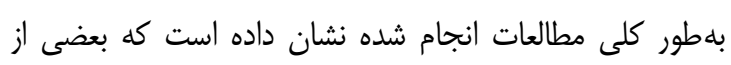
تركيبات موجود در اين كَياه مانند تيموكينون، نيزلون، كارواكرول، سايونينها، آلفا لينولنيك اسيد، كاما لينولنيك و ليمونن داراى اثرات

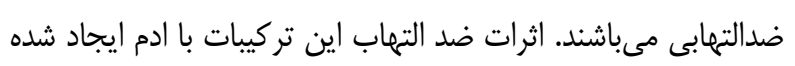

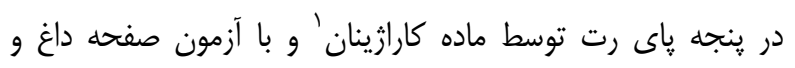

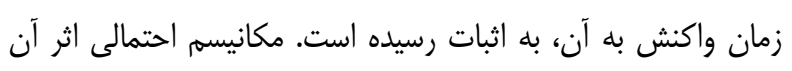

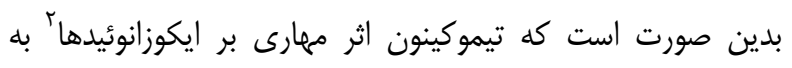
خصوص ترومبو كسان B2 و لكوترين B4 ايجاد مى كند (سا).

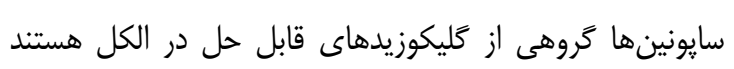

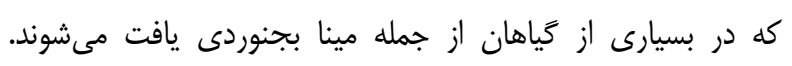
كزارشهاى زيادى در ارتباط با اثرات ضد التهابى آنها وجود دارد.

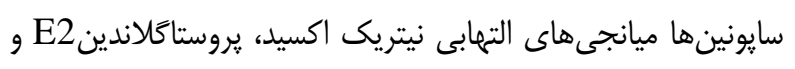

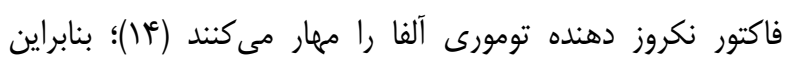

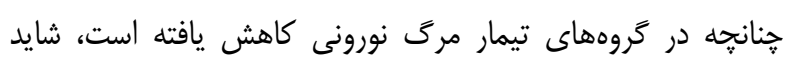
يكى از مكانيسمهاى احتمالى آن اثرات ضد التهابى تركيبات اين نورهات كياه است. متعاقب كميرسيون عصب، در محل ضايعه سويراكسيدها (مولكول هاى اكسيثن با يك الكترون اضافه) و نيتريك اكسايد توليد

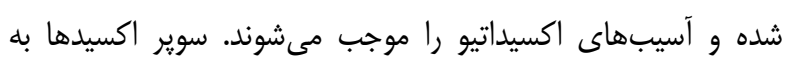

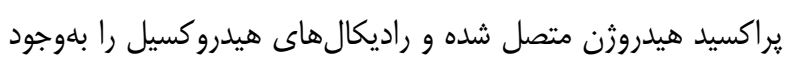

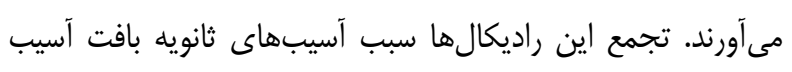

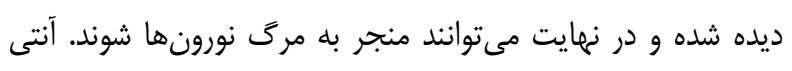
اكسيدانها نقش ارزندهاى در حفاظت نورونى بر عهلده دارند. كياه

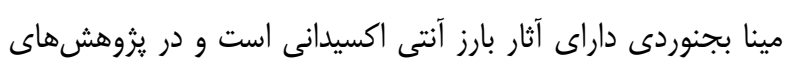

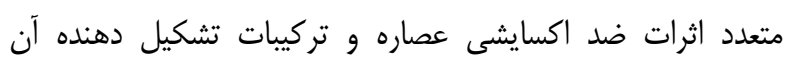

\footnotetext{
${ }^{1}$ Karajinan
} 
حالت طبيعى برمى گردد. به خصوص در فاز آبى كه شكل سلول

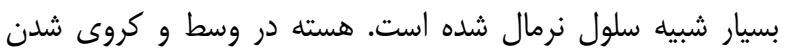
جسم سلولى حكايت از كاهش دزنراسيون و يا افزايش روند ترميه

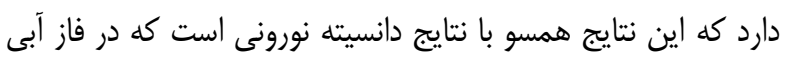
بيشترين افزايش در دانسيته نورونى مشاهده شده است.

\section{نتيجه كيرى}

آناليز دادهها نشان مى دهد كه دانسيته نورونى در تمام كروههاى تيمار نسبت به كروه كميرسيون افزايش يافته است. در اين ميان فاز آبى بيشترين افزايش را داشته است. بلهور كلى اين كياه احتمالاً با فيا

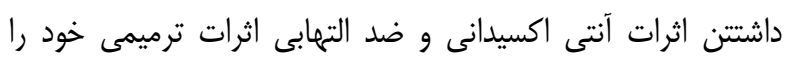

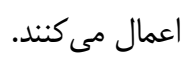

\section{تقدير و تشكّر}

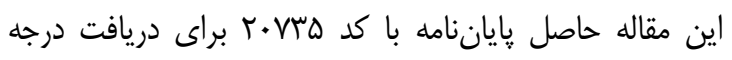
كارشناسى ارشد بود. به اين وسيله از همه همكاران كروه زيست بانس

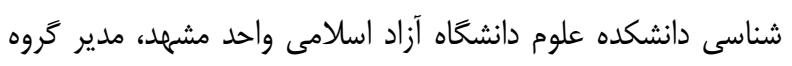

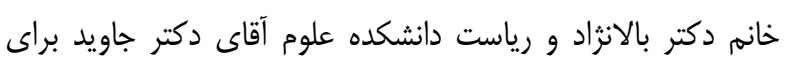
همكارىهاى بىدريخشان تشكر و قدردانى مىشود.

\section{تضاد منافع}

نويسندكان مقاله اعلام مىدارند كه هيج كَونه تضاد منافعى در

$$
\text { ثزوهش حاضر وجود ندارد. }
$$

را كاهش داده و باعث محافظت آنها مى كردد (IV).

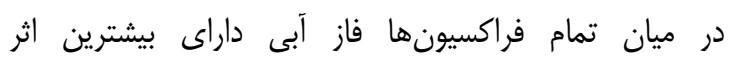

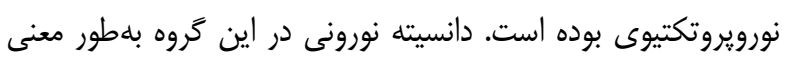

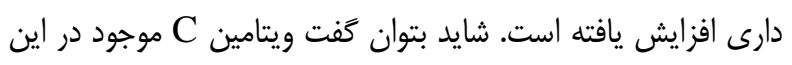

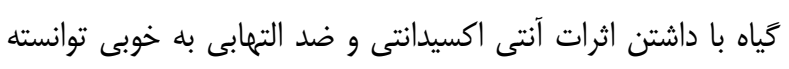

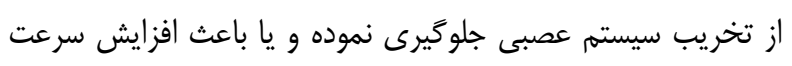

$$
\text { ترميم آن مى تردد. }
$$

در اين يزوهش آناليز دادههاى مربوط به آزمون بررسى اثرات

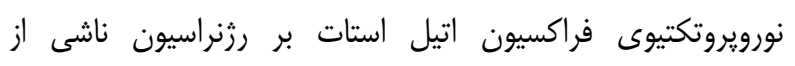
كميرسيون عصب سياتيك در رت نشان داد كه تفاوت معنادارى بين دانسيته نورونى گروه كميرسيون و گروه تيمار فراكسيون اتيل استات

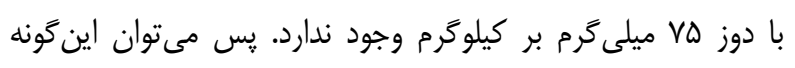

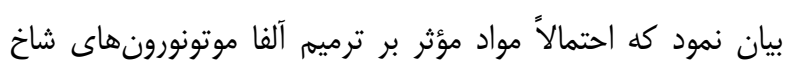
قدامى نخاع، در فراكسيون اتيل استات وجود نداشتهاند، يا مقدار آن - نوان

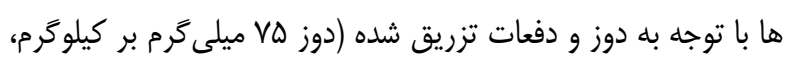

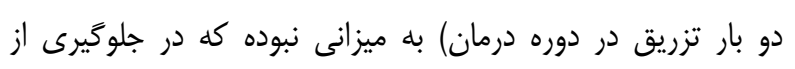

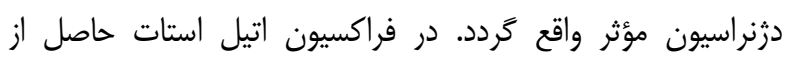

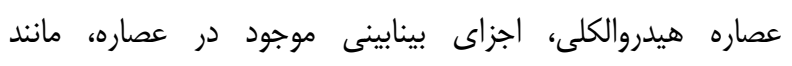

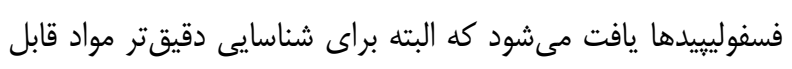

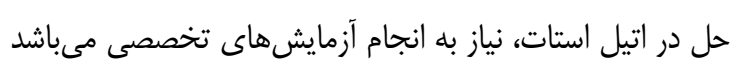

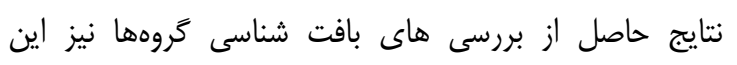

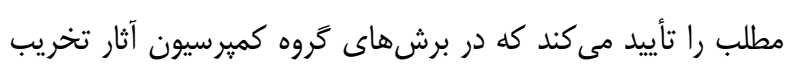

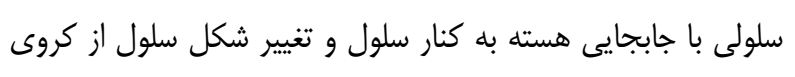

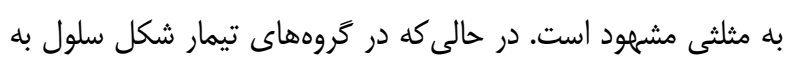

\section{منابع:}

1- Bechmann I.. Failed central nervous system regeneration. Neuromolecular Med. 2005; 7(3): 217-28. DOI: 10.1385/NMM:7:3:217

2- Dahlin LB. and Brandt J. Basic science of peripheral nerve repair: Wallerian degeneration/growth cones. Oper Tech Orthop. 2004; 14(3): 138-45. DOI: 10.1053/j.oto.2004.06.004

3- Fenrich K. and Gordon T. Axonal regeneration in the peripheral and central nervous systems-current issues and advances. Can J Neurol Sci. 2004; 31: 142-56. Link

4- Cimino-Mathews AM. Peripheral nerve sheath tumors. Surg Pathol Clin. 2011; 4(3): 761-82. DOI: 10.1016/j.path.2011.08.004 
5- Jaimand K, Rezaee MB. Chemical constituents of essential oils from Tanacetum balsamita L.J Essent Oil Res. 2005; 17(5): 565-566. DOI: 10.1080/10412905.2005.9698996

6- Susrurluk H, Caliskan Z, Gurkan O, Kırmızıgü S, Goren NB. Antifeedant activity of some Tanacetum species and bioassay guided isolation secondary metabolites of Tanacetum cadmeum ssp. cadmeum (Compositae). Ind Crops Prod. 2007; 26(2): 220- 8. DOI: 10.1016/j.indcrop.2007.04.002

7- Tiuman TS, Ueda-Nakamura T, Garcia Cortez DA, Dias Filho BP, Morgado-Díaz JA, de Souza W, et al. Antileshmanial activity of parthenolide, a sesquiterpene lactone isolated from Tanacetum. parthenium. Antimicrob Agents Chemother. 2005; 49(1): 176- 82. DOI: 10.1128/AAC.49.11.176-182.2005

8- Cicchetti E, Chaintreau A. Comparison of extraction techniques and modeling of accelerated solvent extraction for the authentication of natural vanilla flavors. J Sep Sci. 2009; 32(11): 1957-64. DOI: 10.1002/jssc.200800650

9- Behnam-Rasouli M, Nikravesh MR, Mahdavi-Shahri N, Tehranipour M. Post-Operative time effects after sciatic nerve crush on the number of alpha motoneurons ,using a stereological (Disector). Iran Biomed J. 2000; 4(1): 45-9. Link

10- Tehranipour M. Ghadamyari T. (The effects of root aquatic extract of Salvia staminea on neuronal density of alpha motoneurons in spinal cord anterior horn after sciatic nerve compression in rat. J Biol Sci. 2010; 10(1): 48-52. Link

11- Sterio DC. The unbiased estimation of number and sizes of arbitrary particles using the disector. J Microsc. 1984; 134(Pt 2): 127-36. DOI: 10.1111/j.1365-2818.1984.tb02501.x

12- Johnson EO, Charchant A, Soucacos PN. (2008). Nerve repair: Experimental and clinical evaluation of neurotrophic factors in peripheral nerve regeneration. Injury. 2008; 39(3): 37-42. DOI: 10.1016/j.injury.2008.06.015

13- Hajhashemi V,Ghannadi A, Jafarabadi H. Black cumin seed essential oil, as a potent analgesic and antiinflammatory drug. Phytother Res. 2004; 18(3): 195- 9. DOI: 10.1002/ptr.1390

14- Yuan G, Wahlqvist ML, He G, Yang M Li D. Natural products and anti-inflammatory activity. Asia Pac J Clin Nutr. 2006; 15(2): 143-52. Link

15- Merfort I, WaryV, Barakat HH, Hussein SAM, Nawwar MAM, Wiuhn G. Flavonol triglycosides from seeds of Nigella sativa. Phytochemistry. 1997; 46(2): 359-63. DOI: 10.1016/S0031-9422(97)00296-3

16- Malekpoor F; Pirbalouti AG; Salimi A; Shabani L; Sharifi M; Hamedi B. Antimicrobial and antioxidant activities and total phenolic content of Tanacetum polycephalum Schutz. Bip. as a folkloric herb in South western Iran. Indian J Tradit Knowl. 2015; 14(30): 370-75. Link

17- Misra UK Kalita J. Toxic neuropathies. Neurol India. 2009; 75(6): 697-705. DOI: 10.4103/0028-3886.59463 